\title{
Assessing uncertainties in a second-generation dynamic vegetation model caused by ecological scale limitations
}

\author{
Rosie Fisher ${ }^{1}$, Nate McDowell ${ }^{1}$, Drew Purves ${ }^{2}$, Paul Moorcroft ${ }^{3}$, Stephen Sitch ${ }^{4}$, Peter Cox ${ }^{5,6}$, \\ Chris Huntingford $^{7}$, Patrick Meir ${ }^{8}$ and F. Ian Woodward ${ }^{9}$ \\ ${ }^{1}$ Earth and Environmental Science Division, Los Alamos National Laboratory, Los Alamos, NM, USA; ${ }^{2}$ Microsoft Research, Cambridge, UK; ${ }^{3}$ Department \\ of Organismic and Evolutionary Biology, Harvard University, 22 Divinity Avenue, Cambridge, MA 02138, USA; ${ }^{4}$ Department of Geography, University \\ of Leeds, Leeds, UK; ${ }^{5}$ School of Engineering, Mathematics and Physical Sciences, University of Exeter, Exeter EX4 4QF, UK; ${ }^{6}$ Met Office Hadley Centre, \\ Exeter EX1 3PB, UK; ${ }^{7}$ Centre for Ecology and Hydrology, Wallingford, Oxfordshire, OX10 8BB, UK; ${ }^{8}$ School of Geosciences, University of Edinburgh, \\ Drummond Street, Edinburgh, UK; ${ }^{9}$ Department of Animal \& Plant Sciences, University of Sheffield, Sheffield, S10 2TN, UK
}

\begin{abstract}
Author for correspondence:
Rosie Fisher

Tel: +1 5056656006

Email: rosieafisher@gmail.com
\end{abstract}

Received: 16 March 2010

Accepted: 2 May 2010

New Phytologist (2010) 187: 666-681 doi: $10.1111 /$ j.1469-8137.2010.03340.x

Key words: Amazon, competition, competitive exclusion, dynamic global vegetation model (DGVM), ecosystem demography, migration, perfect plasticity, scaling.

\section{Summary}

- Second-generation Dynamic Global Vegetation Models (DGVMs) have recently been developed that explicitly represent the ecological dynamics of disturbance, vertical competition for light, and succession. Here, we introduce a modified second-generation DGVM and examine how the representation of demographic processes operating at two-dimensional spatial scales not represented by these models can influence predicted community structure, and responses of ecosystems to climate change.

- The key demographic processes we investigated were seed advection, seed mixing, sapling survival, competitive exclusion and plant mortality. We varied these parameters in the context of a simulated Amazon rainforest ecosystem containing seven plant functional types (PFTs) that varied along a trade-off surface between growth and the risk of starvation induced mortality.

- Varying the five unconstrained parameters generated community structures ranging from monocultures to equal co-dominance of the seven PFTs. When exposed to a climate change scenario, the competing impacts of $\mathrm{CO}_{2}$ fertilization and increasing plant mortality caused ecosystem biomass to diverge substantially between simulations, with mid-21st century biomass predictions ranging from 1.5 to $27.0 \mathrm{~kg} \mathrm{C} \mathrm{m}^{-2}$.

- Filtering the results using contemporary observation ranges of biomass, leaf area index (LAI), gross primary productivity (GPP) and net primary productivity (NPP) did not substantially constrain the potential outcomes. We conclude that demographic processes represent a large source of uncertainty in DGVM predictions.

\section{Introduction}

The terrestrial biosphere plays a critical role in regulating the Earth's carbon cycle (Bonan, 2008). There is concern that terrestrial ecosystems may be unable to maintain the current uptake of c. 33\% of anthropogenic emissions (Rodenbeck et al., 2003; Zeng et al., 2005) because of the anticipated negative impact of heating and drying on photosynthesis and survival (Cox et al., 2000; Friedlingstein et al., 2006). For this reason, Dynamic Global Vegetation Models (DGVMs), are now recognized as a critical component of climate change prediction. DGVM models simulate a suite of ecosystem properties from half-hourly carbon and water exchange, through daily growth and tissue turnover, to longer-term processes of reproduction, competition, and mortality. These models have become relatively advanced in their capability to simulate short-term surface gas and energy exchanges and atmospheric $\mathrm{CO}_{2}$ (Sellers et al., 1986; Hickler et al., 2008; Purves \& Pacala, 2008; Mercado et al., 2009; Randerson et al., 2009); by contrast, DGVMs contain relatively simple and poorly tested representations of the processes driving 
long-term changes in vegetation composition - for example recruitment, competition and tree mortality (Moorcroft, 2006). The large structural and parametric uncertainty concerning these processes means that existing DGVMs produce a wide variety of predictions regarding the future strength and direction of the climate carbon cycle feedback (Friedlingstein et al., 2006; Thornton et al., 2007; Sitch et al., 2008). For example, some models predict catastrophic declines in the Amazon and Boreal forests, while others predict relatively stable ecosystem composition and carbon storage, even with the same future climate drivers (as illustrated by Sitch et al., 2008). Model biases introduced by these uncertainties are not readily estimated because limited observations exist to constrain demographic processes under rapidly altering climates (Purves \& Pacala, 2008; Allen et al., 2010).

In an attempt to increase ecological realism in DGVMs, more sophisticated models have recently been developed that explicitly represent the demographic processes of disturbance, recruitment, competition between plant types for light, and tree mortality (Friend \& White, 2000; Moorcroft et al., 2001; Sato et al., 2007; Hickler et al., 2008; Scheiter \& Higgins, 2008). This 'second generation' approach has numerous perceived benefits, including the ability to model regrowth after disturbance, parameterize ecological dynamics directly using tree and plot scale data, and to facilitate the representation of coexistence of different vegetation types by introducing different environmental niches, either along a successional gradient of light availability or vertical strata in the canopy (Moorcroft et al., 2001; Smith et al., 2001; Purves \& Pacala, 2008). The impact of this third property - the ability to simulate competition and coexistence of multiple plant types - is unclear. Successful coexistence of multiple plant functional types (PFTs) might buffer responses to climate change by preventing sudden switches between mono-dominant PFTs. Conversely, relatively stable past climates might discourage the survival of those plant types which invest more resources in the tolerance of extreme climates, at the expense of PFTs with rapid growth rates, making ecosystems in general more susceptible to the effects of climate shifts.

To resolve this issue, it is necessary to understand the processes that control community structure in secondgeneration models. In this paper, we present developments to a second-generation DGVM that facilitate the coexistence of plant functional types. We then identify several poorly constrained processes that fundamentally influence how community structure emerges from plant demography. These include seed advection, seed mixing, sapling mortality, competitive exclusion and stress-induced tree mortality. While representations of these ecological processes are typically present in current DGVMs, they all depend upon two-dimensional spatial scales not represented by these models. For example, rates of seed mixing and advection rates are properties of landscape heterogeneity, while the stochasticity or determinism of competitive exclusion and the rate of tree mortality under stress are both properties of multiscale environmental heterogeneity (Clark et al., 2007). DGVMs are spatially one-dimensional, as they consider single points in space that do not interact with one-another. Therefore, it is not possible to explicitly represent these processes in the current modelling context, and instead their impact must be parameterized. In this paper, we identify five demographic processes whose outcome depends on the sub-grid spatial heterogeneity of a landscape, and investigate how the parameterizations affect the outcome of a onedimensional dynamic vegetation model.

In this paper, we use the Ecosystem Demography model (ED, Moorcroft et al., 2001), a size- and age-structured DGVM that occupies a mid-point on the continuum from gap models (Sato et al., 2007; Hickler et al., 2008) that contain representations of individual trees, to area-based DGVMs, which model the fate of a single average individual for each PFT (Cox, 2001; Bonan et al., 2003; Sitch et al., 2003; Woodward \& Lomas, 2004; Krinner et al., 2005). Because of this, ED is perceived as a promising template for a second generation of land surface models, appropriate for inclusion in large-scale climate simulations (Meir et al., 2006; Moorcroft, 2006; Prentice et al., 2007; Huntingford et al., 2008; Purves \& Pacala, 2008).

\section{Description}

\section{Background}

In order to provide a realistic context for our study, we situate our hypothetical ecosystem in the eastern Amazon basin, and parameterize carbon fluxes and plant allocation using recently compiled data from three intensively studied forest plots (Malhi et al., 2009b). Further details are given in Supporting Information Notes S1 and Table 2. A majority of Global Climate Models, (GCMs) predict that dry season rainfall over Amazonia will decline (Malhi et al., 2009a), and that temperatures will increase (Salazar et al., 2007). This makes the Amazon an ideal place to investigate the impact of alternative community structures on future vegetation structure and function. For a more complete review on prognoses for the Amazon rainforest see Cox et al. (2004, 2008), Huntingford et al. (2008), Malhi et al. (2008, 2009b), Meir et al. (2008) and Nepstad et al. (2008).

\section{Ecosystem Demography model}

The ED model is a size- and age-structural approximation of a gap model, the state structure of which is a nested hierarchy of geographical grid cells, landscape age-classes and cohorts of trees of different sizes and PFTs. The landscape age-classes are designed to capture horizontal 
biotic heterogeneity in canopy structure that arises from various forms of disturbance. Biotic heterogeneity does not include physical aspects of sub-grid heterogeneity such as variations in altitude, soils or aspect. These are not accounted for in the model structure. At each daily timestep, canopy tree mortality creates new areas of disturbed ground. To make the model computationally more efficient, the spatial locations of the disturbed areas are not specified, and thus can be tracked as a single landscape ageclass that represents the aggregation of canopy-gap sized areas within each grid cell that were disturbed at a similar time in the past. To minimize the proliferation of landscape age-classes, the vertical structure and composition of model land classes are continually compared with each other and merged if they are sufficiently similar.

New juvenile individuals of each PFT are recruited on a daily time-step, based on the reproductive output of existing individuals of the same PFT. Individuals located in the same landscape age-class, PFT and size, are tracked as 'cohorts'. Each cohort is defined by the number of individuals per unit area $\left(n_{\mathrm{c}}\right)$, and a single representative tree, defined by its structural biomass $\left(b_{s}\right)$, which is a function of tree diameter $D(\mathrm{~cm})$, and live biomass $\left(b_{\mathrm{a}}\right)$, which consists of leaf $\left(b_{1}\right)$, fine root $\left(b_{\mathrm{r}}\right)$ and sapwood $\left(b_{\mathrm{sw}}\right)$ (all in kg C per individual $\left.\mathrm{yr}^{-1}\right)$. As with the landscape age-classes, cohorts are continually compared and subsequently fused if they are in the same PFT, landscape age-class and are close in size. Through this procedure, the ED model explicitly tracks horizontal and vertical heterogeneity in canopy structure.

In the next section, we discuss model representations of recruitment, competition and mortality. Because these processes operate in two-dimensional spatial space and therefore have no analogue in a one-dimensional model, parameterization from field observations is difficult. We introduced modifications to these processes, but unless otherwise stated, the model is the same as EDv1.0, as described by Moorcroft et al. (2001). Alterations made to the energy and gas exchange algorithms are described in Notes S1.

\section{Modelling sapling recruitment}

Sapling recruitment is the sum of plant reproduction from local (internal) and nonlocal (external) sources. The smallest units considered by the model are $2.5 \mathrm{~m}$ high saplings, we do not model the germination of seeds and early seedling development, but seed dispersal processes are nevertheless responsible for the location of the resultant saplings. External recruitment represents the advection of seeds from other geographical areas. Seed advection $\left(A_{s}\right)$ from multiple directions, results in a point-specific sapling establishment rate measured in individuals $\mathrm{m}^{-2}$ per $\mathrm{PFT}^{-1} \mathrm{yr}^{-1}$. As the distribution of different environmental conditions within a grid cell is not represented in the model, we use the null assumption that PFT advection is constant through time and that the number of saplings recruited per PFT is equal. For internal recruitment, a fixed fraction, $f_{\text {repro }}$ of the carbon available for growth $\left(C_{g}\right.$, Eqn 7$)$ is partitioned into reproduction. The number of saplings per PFT is calculated from this carbon supply divided by the biomass required to make each $2.5 \mathrm{~m}$ sapling. The internally generated saplings are distributed between landscape age-classes. This requires an estimate of $X_{\mathrm{m}}$ : the probability that a propagule generated in one landscape age class establishes in a different landscape class from that of its parents. In other words, $X_{\mathrm{m}}$ represents how well mixed seeds are across a landscape with respect to the landscape age-class gradient. Low levels of 'seed mixing' mean that seeds are likely to land near their parent tree, and vice-versa. Subsequently, a 'sapling mortality' is applied $\left(M_{s}\right)$ the value of which represents the discrepancy between the maximum number of saplings and the number that are realized in the model. The total number of new established saplings in each time-step, $N_{\text {sapling, }}$, is therefore:

$N_{\text {sapling }}=A_{\mathrm{s}}+C_{\mathrm{g}}\left(1-M_{\mathrm{s}}\right) /\left(f_{\text {repro }} b_{0}\right) t$

Eqn 1

where $t$, length of each daily time-step, in years $(1 / 365)$; and $b_{0}$ is the sapling biomass.

The parameters $A_{\mathrm{s}}$ and $X_{\mathrm{m}}$ both depend upon the spatial structure of the landscape and the likelihood of ecosystems with different composition existing in close proximity. In a two-dimensional spatial model of interconnected patches (Kneitel \& Chase, 2003; Leibold et al., 2004; Lischke et al., 2006) parameters representing the spatial movement of propagules would not be necessary, as they would be modelled with diffusion type equations; however, without this capacity, we must parameterize the processes of seed dispersal within a grid cell. Here, we investigate how the parameterization of seed advection and seed mixing affect community structure in a sensitivity analysis.

\section{Modelling canopy structure and coexistence}

In the original EDv1.0 model (Moorcroft et al., 2001) there were no explicit spatial dimensions associated with each cohort, so the hypothetical leaf area of each tree extended across the entire surface of the landscape age class, effectively creating a steep vertical light profile that caused unrealistic levels of shade-induced competitive exclusion and reduced the capacity to simulate coexistence of plants within a successional age class. Resolving these issues requires representation of the physical dimension of tree crowns. We adopted and modified the Perfect Plasticity Approximation (PPA) of Purves et al. (2008b). Based on the observation that tree crowns often occupy gaps in the canopy that are spatially dislocated from the base of the tree, 
PPA assumes that the horizontal plasticity of crown location and shape is infinite but that trees have realistic relationships between crown area and height. The end result is that when the total canopy area is greater than the total ground area, the canopy is considered to be 'closed' and breaks into distinct layers, each consisting of those cohorts with heights within a particular range, such that each cohort occurs in only one layer; in a situation with two layers, that is, canopy and understory, the cohorts are assigned to the canopy or understory according to their height relative to a mean canopy intersection height ' $z$ '. Trees within the same layer do not shade each other at all and trees in a given layer are uniformly shaded according to the total leaf area index (LAI) above the top height of that layer. This scheme means that a small increase in height of a cohort no longer confers a large competitive advantage, except where cohorts cross $z^{*}$.

The original version of the PPA model assumes that $z^{*}$ is spatially uniform within a stand; however, canopy intersection heights vary spatially such that a tree of height ' $h$ ' might sometimes be in the canopy and sometimes be in the understory, depending on its circumstances. The assumption that $z^{*}$ is spatially uniform, exacerbated by the fact that ED typically aggregates the canopy into far fewer cohorts than the original PPA method of Purves et al., 2008 b, generates a highly deterministic model of competition, whereby a single cohort with a small height advantage might come to quickly and unrealistically dominate the entire canopy. It is therefore difficult to represent coexistence between similar PFTs without including some potential for $z^{*}$ to be heterogeneous. Clark et al. $(2003,2007)$ propose that deterministic models of coexistence often fail because they do not properly account for unobserved lifehistory trade-offs, neglected genetic variation or spatial heterogeneity in topology, soil type, aspect and dispersal and recruitment processes, they term these factors 'random individual effects'. In the context of the PPA model, this is analogous to the possibility that $z^{*}$ is spatially heterogeneous.

We introduced the potential influence of 'random individual effects' on community composition by aggregating all the processes that suppress the ability of the fastest growing PFTs to monopolize resources into a single 'competitive exclusion' parameter $C_{\mathrm{e}}$. This parameter controls the probability that a tree of a given height will obtain a space in the canopy of a closed forest. The forest canopy is considered as closed when the total canopy area $\left(A_{\text {canopy }}, \mathrm{m}^{2}\right)$, which is the sum of all the crown areas $\left(A_{\text {crown }}, \mathrm{m}^{2}\right)$

$A_{\text {canopy }}=\sum A_{\text {crown }}$,

Eqn 2

exceeds the ground area of the age class in question $\left(A_{\mathrm{p}}\right)$. Under these circumstances, the 'extra' crown area $A_{\text {loss }}$
$\left(A_{\text {canopy }}-A_{\mathrm{p}}\right)$ is moved into the understorey. For each cohort already in the canopy, we determine a fraction of trees that are lost from the canopy $\left(L_{\mathrm{c}}\right)$ and moved to the understory. $L_{\mathrm{c}}$ is calculated as

$L_{\mathrm{c}}=A_{\mathrm{loss}} w_{\mathrm{c}} / \sum\left(w_{\mathrm{c}}\right)$

Eqn 3

where $w_{\mathrm{c}}$ is a weighting of each cohort determined by basal diameter $D(\mathrm{~cm})$ and the competitive exclusion coefficient $C_{\mathrm{e}}$

$w_{\mathrm{c}}=D^{\mathrm{C}_{\mathrm{e}}}$

Eqn 4

The higher the value of $C_{\mathrm{e}}$, the greater the impact of tree diameter on the probability of a given tree obtaining a position in the canopy layer. That is, for high $C_{\mathrm{e}}$ values, competition is highly deterministic. Small average differences between cohorts are still significant because there is little randomness at the scale of individual trees. Therefore, faster-growing trees monopolize light resources more effectively, leading to competitive exclusion of slowergrowing trees. By contrast, low values of $C_{\mathrm{e}}$ imply that the outcome of competition is stochastic: small differences between cohorts do not matter greatly because randomness at the scale of individual trees is such that all cohorts suffer approximately equally from competition for canopy space. The smaller the value of $C_{\mathrm{e}}$, the greater the influence of random factors on the competitive exclusion process, and the higher the probability that slower-growing trees will get into the canopy. Appropriate values of $C_{\mathrm{e}}$ are poorly constrained (Clark et al., 2003, 2007), thus we investigated the effects of a wide range of $C_{\mathrm{e}}$ values on community structure and biomass predictions.

\section{Modelling plant mortality}

Modelling community composition requires accurate simulation of the processes controlling mortality of different plant types. Mechanistic prediction of plant mortality is currently a developing field (McDowell et al., 2008) and the dominant mechanism of death remains unclear. Two potential physiological mechanisms underlying plant susceptibility to climate extremes and attack by biotic mortality agents include hydraulic failure caused by excessive xylem embolism and carbon starvation because of stomatal closure and subsequent depletion of available carbohydrate reserves used for maintenance and defence. Although not yet understood sufficiently well to model, metabolic limitations induced by restrictions on phloem transport and tissue dehydration may exacerbate carbon starvation (Körner, 2003; McDowell \& Sevanto, 2010; Sala et al., 2010). Isohydric plants, which close their stomata during drought 
conditions, may be more likely to suffer carbon starvation than hydraulic failure (McDowell et al., 2008, Adams et al., 2009). Fisher et al. (2006) observed that leaf physiology was consistent with isohydric habit in Amazonian rainforest trees and Metcalfe et al. (2010) provide evidence suggesting that the carbon budget and timing of death of artificially droughted rainforest trees is consistent with death from carbon starvation. Therefore, in this paper, we concentrate on carbon starvation as the likely mode of mortality. To simulate carbon starvation, we define a new 'stored carbon' pool, $b_{\text {store }}(\mathrm{kg} \mathrm{C}$ per individual), and model allocation to this pool using the widespread observation that relative partitioning of photosynthate to storage increases during periods when photosynthesis is low (Gibon et al., 2009; McDowell \& Sevanto, 2010; Smith \& Stitt, 2007). Allocation to the store is thus altered according to the size of the existing pool and a 'target' quantity $S^{*}$, multiplied by leaf biomass, $b_{1} . S^{*}$ is an indicator of the generic strategy plants undertake to avoid carbon starvation. The more carbon that is kept back for storage, the more likely it is that a plant can survive periods of negative carbon assimilation (McDowell et al., 2008). The carbon balance $\left(C_{\mathrm{b}}\right)$ available for storage, growth and reproduction is determined as

$$
C_{\mathrm{b}}=\mathrm{NPP}-m_{\mathrm{d}}
$$

the balance of net primary productivity (NPP) and tissue turnover requirements $\left(m_{\mathrm{d}}\right.$, see Notes $\mathrm{S} 1$ ), both in $\mathrm{kg} \mathrm{C}$ per individual $\mathrm{yr}^{-1}$ ). The balance of stored carbon to target stored carbon $f_{s}$ :

$f_{\mathrm{s}}=b_{\text {store }} /\left(S^{*} b_{1}\right)$

Eqn 6

is used to predict the flux of carbon to the storage pool as a fraction of the carbon balance $\left(f_{\text {store }}\right)$

$f_{\text {store }}=\mathrm{e}^{-4 f_{\mathrm{s}}}$

Eqn 7

The form of the function depicts a situation whereby carbon allocation approaches 1.0 when the store is low, and approaches zero when the store is higher than the target quantity. Flux to and from the store is calculated as:

$\Delta b_{\text {store }}=C_{b} \cdot f_{\text {store }}$

Eqn 8

Thus if $C_{\mathrm{b}}$ is negative (if NPP is less than maintenance demands, such as in winter or drought periods) carbon is removed from the store. Mortality increases as $b_{\text {store }}$ declines below a threshold (see Eqn 10), so negative $b_{\text {store }}$ is avoided by gradual cohort death. Otherwise, the carbon remaining for growth and reproduction $\left(C_{\mathrm{g}}, \mathrm{kg} C\right.$ per individual $\mathrm{yr}^{-1}$ ) is what remains once allocation to the store has been removed.
$C_{\mathrm{g}}=C_{\mathrm{b}}\left(1.0-f_{\text {store }}\right)$

Eqn 9

Because each cohort in ED represents the hypothetical means of a set of trees with broadly similar but nonetheless variable genetic composition and environmental conditions, the prediction of mortality based on a single threshold carbon storage value is inappropriate. In this case, we model mortality rate $M$ (fraction of trees dying $\mathrm{yr}^{-1}$ ) as a function of the ratio of $b_{\text {store }}$ to leaf biomass where $b_{\text {store }}<b_{1}$

$M=B_{\mathrm{m}}+S_{\mathrm{m}} \min \left(1.0,\left(b_{l}-b_{\text {store }}\right) / b_{1} \quad\right.$ Eqn 10

Background mortality, $B_{\mathrm{m}},\left(1.39 \% \mathrm{yr}^{-1}\right.$, Chao et al. (2008) occurs irrespective of the stress on the carbon store. $S_{\mathrm{m}}$ is the mortality rate (fraction $\mathrm{yr}^{-1}$ ) of a single cohort when mean cohort carbon storage is zero. The value of $S_{\mathrm{m}}$ is also affected by spatial heterogeneity. In the hypothetical 'average' stand modelled by a DGVM, an 'average' tree may die (making its observed mortality 100\%) because its carbon reserves fall to zero. In reality it is unlikely that, across a whole grid cell, all of the trees in a given PFT and size class will die simultaneously. Because we can neither parameterize effectively nor simulate the sub-grid cell heterogeneities that lead to the discrepancy between stand-level and landscapelevel mortality, it is necessary to parameterize the variable $S_{\mathrm{m}}$ as the impact of carbon deficit on mortality rates.

\section{Plant functional types}

Plant ecology models typically seek to explain the coexistence of species along functional 'trade-offs' (Pacala et al., 1996; Moorcroft et al., 2001; Kneitel \& Chase, 2003; Baraloto et al., 2005; Falster 2006). These compromises in plant form and function mean that no species is the best competitor in all environments. We use variation in $S^{*}$ to represent an example of a growth vs mortality risk trade-off surface (Hacke et al., 2006; Poorter et al., 2010). We constrain $S^{*}$ using measurements of carbon storage from a rainforest in Panama (Würth et al., 2005), in which the average amount of carbon stored in trees was approximately the same as that required to replace all of the leaf and fine root biomass. Notably, variation between species was substantial. We calculated the range of carbon stored between species using the data on percentage carbon storage in different tissues, and the mean biomass of each tissue type (Würth et al., 2005), and found that carbon storage varied by a factor of 2.4 (or 3.7, if one species with extremely high levels of stem carbohydrate was taken into account). Reflecting this, we created an array of seven tropical, evergreen PFTs that differed in $S^{*}$ from 1.0 for PFT2, to 2.5 for PFT7 (Table 1). The additional properties of these PFTs are described in Table 2. Each PFT represents a class of species that is broadleaf, evergreen and tropical, but with a specific range of carbon storage behaviour. 
New

Phytologist

Table 1 Value of $S^{*}$, the 'target' carbon storage criteria between plant functional types (PPTs)

\begin{tabular}{ll}
\hline PFT number & $S^{*}$ \\
\hline 1 & 1.0 \\
2 & 1.25 \\
3 & 1.5 \\
4 & 1.75 \\
5 & 2.0 \\
6 & 2.25 \\
7 & 2.5 \\
\hline
\end{tabular}

$S^{*}$ is the quantity of carbon targeted by the allocation scheme, in multiples of the total leaf biomass $\left(b_{1}\right)$. The range of values chosen is based on observations by Würth et al. (2005).

\section{Methods}

To develop a DGVM capable of predicting vegetation conditions under altered climate and $\mathrm{CO}_{2}$, we coupled the adapted ED model to the Met Office Surface Exchange Scheme (MOSES II, Essery et al., 2003), that has recently evolved into joint UK land environment simulator (JULES) (Mercado et al., 2007). JULES calculates the land surface gas exchange and provides fluxes of carbon to ED, which generates land surface and canopy structure to drive the land-atmosphere interactions in return. We term the coupled model JULES-ED.

We drove JULES-ED using output from the IMOGEN analogue climate model (Huntingford \& Cox, 2000). IMOGEN utilizes pattern output from the Hadley Centre HADCM3-LC Global Circulation Model (Cox et al., 2000) to provide climatic anomalies between a baseline climate and a given climate change scenario. In this instance, we use the Climate Research Unit (CRU, University of East Anglia, Norwich, UK.) 1900-1999 climatology as a baseline dataset onto which we superimpose these anomalies. In order to use both the historical climatology for spin-up, and the pattern output from the GCM to generate forward predictions, the simulations are not site specific. Instead, we utilize data from Malhi et al. (2009b) who synthesized observations of the carbon economy of three Amazonian sites (Manaus, Caxiuanã and Tapajòs) to parameterize the ecophysiology of rainforest ecosystems (see Notes S1). We use driving climatologies for a $3.25 \times 2.5$ grid cell, the south west corner of which is located at $56.25^{\circ} \mathrm{W}$ and $-2.5^{\circ} \mathrm{S}$, encompassing all three sites used by Malhi et al. (2009b).

\section{Model sensitivity tests}

To investigate how uncertainties in the parameterization of demographic processes affect the development of community structure, we conducted a global sensitivity test to five parameters; seed advection $\left(A_{\mathrm{s}}\right)$, seed mixing $\left(X_{\mathrm{m}}\right)$, sapling mortality $\left(M_{\mathrm{s}}\right)$, competitive exclusion $\left(C_{\mathrm{e}}\right)$ and stressinduced adult mortality rate $\left(S_{\mathrm{m}}\right)$. For each parameter, we set high and low parameter boundaries and conducted a 200-member Latin Hypercube exploration (Iman \& Conover, 1982) of the five-dimensional parameter space to identify how different combinations of these processes affect community structure. The parameter ranges for $X_{\mathrm{m}}, C_{\mathrm{e}}$ and $S_{\mathrm{m}}$ were between zero and one because these were the logical endpoints of these processes. For $A_{\mathrm{s}}$ the minimum input was 0 and the maximum upper limit was 50 individual $\mathrm{ha}^{-1} \mathrm{yr}^{-1}$. For $M_{\mathrm{s}}$ the maximum rate was 1.0 , while we set the minimum as $95 \%$. The model results described later illustrate that the output appears to be insensitive beyond these ranges for $A_{\mathrm{s}}$ and $M_{\mathrm{s}}$.

For each ensemble member, we ran the model for $400 \mathrm{yr}$, starting from bare ground in 1700. For the baseline climatology we use $100 \mathrm{yr}$ of CRU data randomized over these $400 \mathrm{yr}$ (except for the 20th century, where we use actual year numbers). To this we added climate anomalies generated by the IMOGEN model driven $\mathrm{CO}_{2}$ concentrations from the HADCM3-LC coupled climate carbon

Table 2 Model parameters obtained from literature sources

\begin{tabular}{lllll}
\hline Parameter & Explanation & Units & Value & Source \\
\hline$M_{\mathrm{b}}$ & Background mortality & $\%$ & 1.39 & Chao et al. (2008) \\
$D$ & Wood density & $\mathrm{g} \mathrm{C} \mathrm{cm}^{-3}$ & 0.7 & Chao et al. (2008) \\
$a_{\text {leaf }}$ & Leaf turnover & $\mathrm{yr}^{-1}$ & 0.69 & Wright et al. (2004) \\
$a_{\text {root }}$ & Fine root allocation & $\mathrm{yr}^{-1}$ & 0.69 & Malhi et al. (2009b) \\
$a_{\text {wood }}$ & Coarse wood turnover (branches \& coarse roots) & $\mathrm{yr}^{-1}$ & 0.01 & Malhi et al. (2009b) \\
$\mathrm{SLA} \mathrm{f}_{\mathrm{c}}$ & Specific leaf area (canopy) & $\mathrm{cm}^{2} \mathrm{~g}^{-1}$ & 87 & Carswell et al. (2002) \\
$\mathrm{SLA}_{\mathrm{u}}$ & Specific leaf area (understory) & $\mathrm{cm}^{2} \mathrm{~g}^{-1}$ & 145 & Carswell et al. (2002) \\
$r_{\mathrm{r}}$ & Root respiration as a fraction of leaf respiration & Fraction & 0.50 & Malhi et al. (2009b) \\
$r_{\mathrm{s}}$ & Stem respiration as a fraction of leaf respiration & Fraction & 0.63 & Malhi et al. (2009b) \\
$K_{\mathrm{N}}$ & Exponent of change in nitrogen through canopy & - & 0.17 & Mercado et al. (2007) \\
$N_{\mathrm{O}}$ & Nitrogen concentration at canopy top & KgN KgC & 0.046 & Mercado et al. (2007) \\
$f_{\text {repro }}$ & Fraction of growth carbon to respiration & Fraction & 0.37 & P Meir et al. (unpublished) \\
\hline
\end{tabular}


cycle model output (Cox et al., 2000; Friedlingstein et al., 2006; Sitch et al., 2008). This climate change scenario is among the most extreme for Amazonia (Malhi et al., 2009a), but appears consistent with recent climate variability in this region (Cox et al., 2004, 2008; Jupp et al., 2010). The annual $\mathrm{CO}_{2}$, precipitation and temperature components of the model drivers are shown in Fig. 1.

\section{Results and Discussion}

\section{Impact of parameter variation on ecosystem biomass} responses to climate change

Altering the five demographic parameters that control unconstrained spatially mediated demographic processes had a profound influence on the predicted response of ecosystem biomass to future $\mathrm{CO}_{2}$ and climate (Fig. 2a). Biomass estimates in 2005 ranged from 6.6 to $22.1 \mathrm{~kg} \mathrm{C} \mathrm{m}^{-2} \mathrm{yr}^{-1}$. By 2050, the competing effects of increasing mortality and productivity in the future scenarios create an even wider divergence in biomass (3.25$27.0 \mathrm{~kg} \mathrm{C} \mathrm{m}^{-2} \mathrm{yr}^{-1}$ ). Some ensemble members are able to benefit from $\mathrm{CO}_{2}$ fertilization, while others are more rapidly affected by the increasingly severe drought events (Fig. 1). Between 2059 and 2060, there is a large drought event that depletes the carbon store and causes mortality in even the most conservative plant functional types. By 2100 , plant biomass is heavily depleted in most scenarios, with the

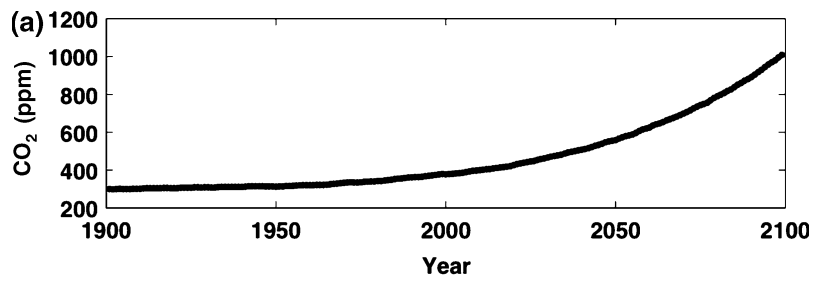

(b)
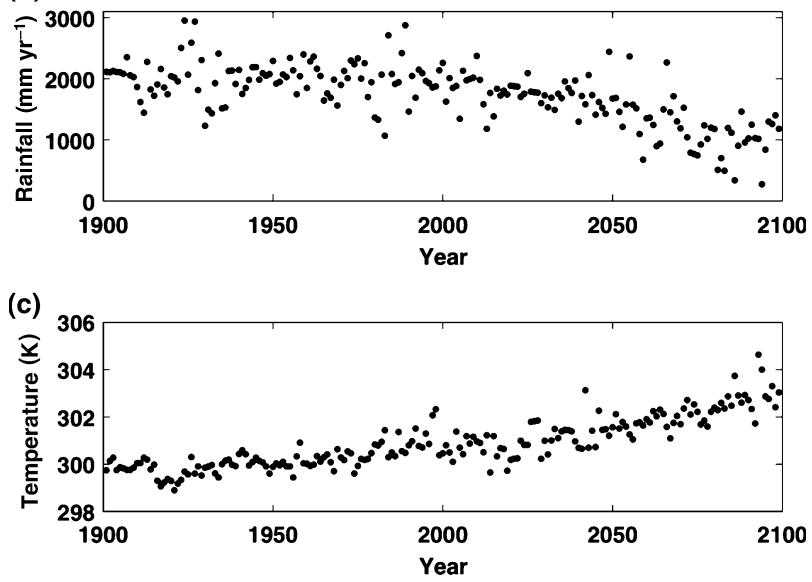

Fig. 1 Forcing data for model simulations: (a) carbon dioxide concentrations, (b) temperature and (c) annual precipitation. most resilient scenario supporting $9.6 \mathrm{~kg} \mathrm{C} \mathrm{m}^{-2}$. The response of LAI to changing climate and $\mathrm{CO}_{2}$ is both less extreme and differs less between runs as LAI recovers more quickly after disturbance and is therefore less affected by variations in ecosystem demography. We emphasize that, owing to the random selection of baseline climate, this illustration is not meant to be proscriptive of the actual future climate or vegetation in particular years.

\section{Filtering unrealistic ensemble members}

The parameter space exploration generated wide variation in ecosystem properties for the present day (Fig. 2a); however, many of the ensemble members generated unrealistic predictions for ecosystem properties that can be constrained by current observations. We filtered those ensemble members whose biomass, GPP, NPP or LAI fell outside observed ranges (Malhi et al., 2009b; Fisher et al., 2007; Brando et al., 2008). To account for measurement error in the upper and lower boundaries of the observations, we extended the ranges by $10 \%$ on either side. After the filtering process, 14 ensemble members remained whose estimates of all four variables were inside the observed ranges (Fig. 2b). While there are many fewer simulations in the filtered set, the spread of predictions is not substantially reduced, with biomass in year 2050 still ranging from 2.6 to $27.0 \mathrm{~kg} \mathrm{C} \mathrm{m}^{-2} \mathrm{yr}^{-1}$. Filtering with this particular set of model metrics did not allow us to constrain the different model futures or rule out either the extremely sensitive or extremely resistant scenarios. Therefore, satisfactory approximation of contemporary ecosystem observations is not necessarily an indicator that a model will produce accurate future predictions. Current efforts to 'benchmark' vegetation models with sets of basic ecosystem data, with the intention of constraining the range of future predictions, should consider this possibility when interpreting their results (Randerson et al., 2009). It is possible that additional filters not used in this experiment, notably responses of forest to experimental drying (Fisher et al., 2007; Brando et al., 2008) might provide more appropriate filtering data. These kinds of plot-level observations are not yet considered in DGVM benchmarking exercises, however, owing to the difficulties involved in precisely replicating the experimental conditions in DGVM models.

\section{Community structure and its relation to ecosystem biomass predictions}

Fig. 3 illustrates the different plant community structures found in the 14 runs that met the filtering criteria. The panels are ordered according to their predicted ecosystem biomass in 2050 (from low to high). Those runs where forest mortality events were predicted to occur sooner, and biomass in 2050 was consequentially lower (e.g. Fig. 3 - top 
New

Phytologist

Fig. 2 Response of the trajectory of total plant biomass to alterations in ecological parameterizations showing the last $150 \mathrm{yr}$ of the 400 yr simulation. (a) Includes all 200 members of the ensemble and (b) includes only those 14 ensemble members with acceptable biomass, leaf area index (LAI), gross primary production (GPP) and net primary productivity (NPP) compared with observations. Shading on symbols indicates the sapling mortality $\left(M_{s}\right)$ parameter for each run, and can be read from Fig. 5(d).
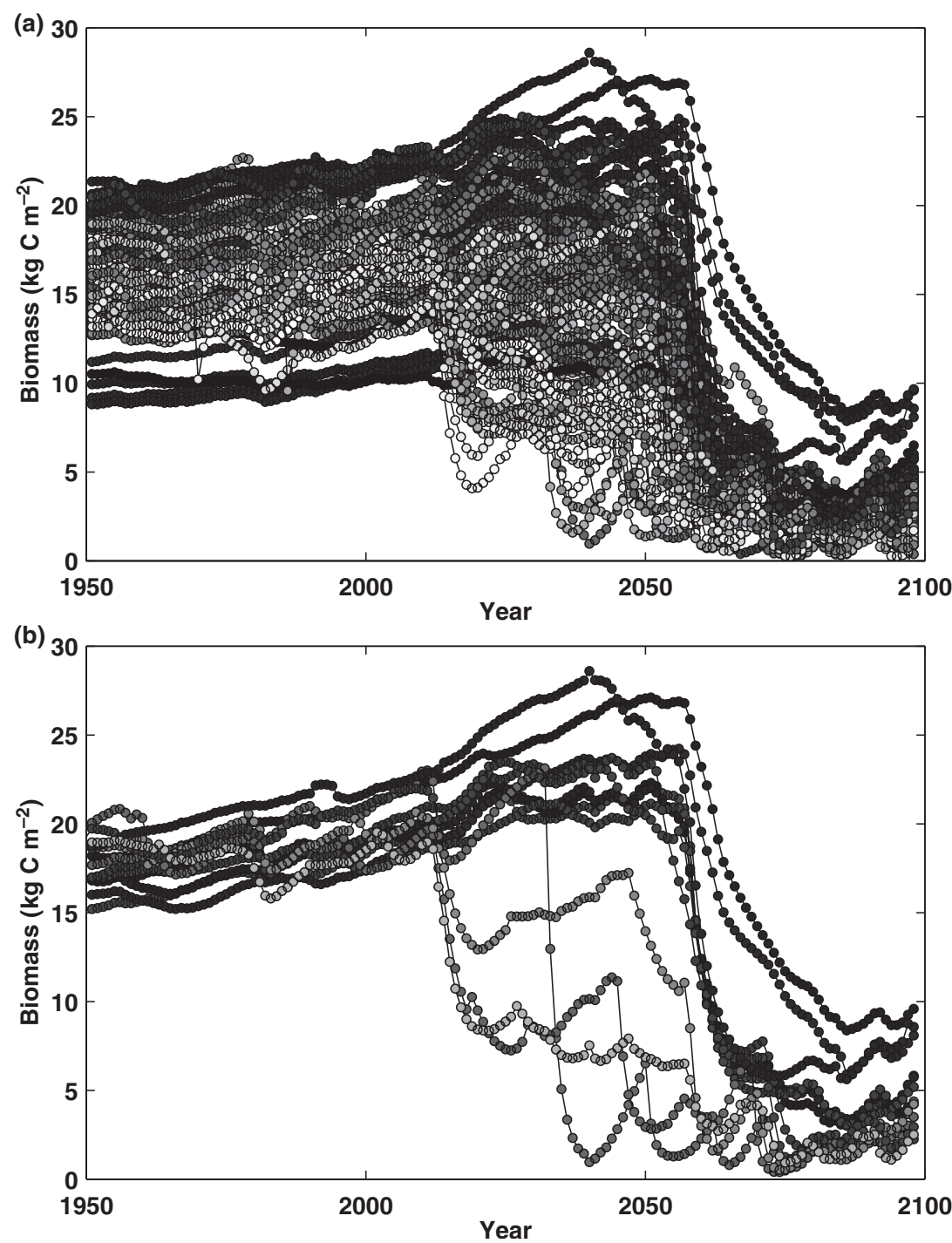

two rows), were dominated by the fast-growing PFT 1 (filled circles), while those runs where the ecosystem avoided biomass collapse for longer tended to have a more equitable distribution of PFTs (e.g. Fig. 3 - bottom two rows). In this particular model scenario, prevailing conditions before 2000 typically favour the dominance of the fastest-growing plant types. The persistence of PFT1 as the dominant plant type in 2000 reflects the relatively benign climatic conditions over the last century and is consistent with a small fitness cost associated with low rates of carbon storage: NPP rarely falls sufficiently to deplete stored carbon reserves enough cause canopy tree mortality. In all cases, the fastest-growing PFTs gain a slight initial advantage via lower allocation to carbon storage. The eventual community structure, however, depends upon the strength of processes that reinforce this initial dominance, which is affected substantially by varying the spatially mediated parameters in this sensitivity test.
Impact of individual parameters on community structure and ecosystem properties

Illustrating detailed ecosystem composition for every ensemble member was impractical, so we reduced the dimensionality of the output by calculating a PFT range. $R_{\mathrm{p}}$, for each model run, as

$R_{\mathrm{p}}=B_{\mathrm{f}, 1}-B_{\mathrm{f}, 7}$

Eqn 11

where $B_{\mathrm{f}, \mathrm{i}}$ is the fractional biomass of the $i$ th PFT in 2000 . Fractional biomass is the total of the total biomass accounted for by a given PFT. Values close to 1 indicate dominance the fastest-growing PFT and values close to zero indicate more equitable PFT distribution. This metric of community structure provides a single value with which to represent how much the community is dominated by fastgrowing plants. Fig. 4 illustrates how this measure of 

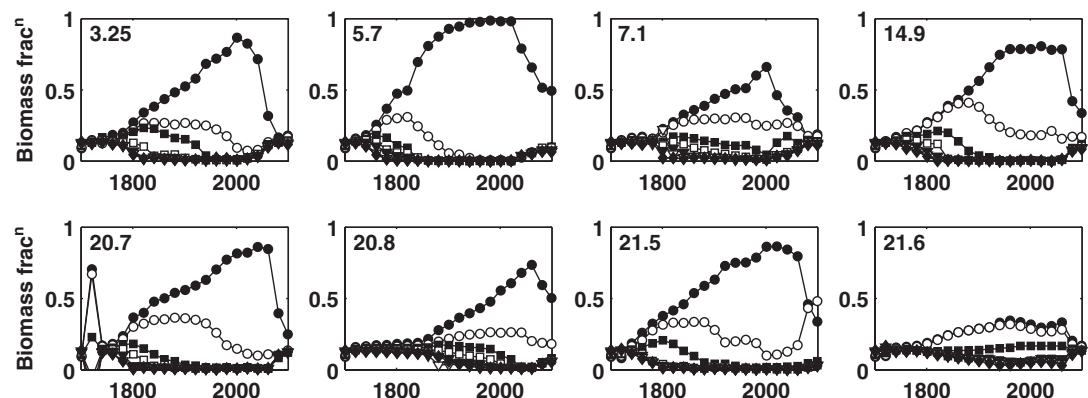

Fig. 3 Development of plant functional type (PFT) community composition over $400 \mathrm{yr}$ model evaluation for each of 16 ensemble members with acceptable values of biomass,
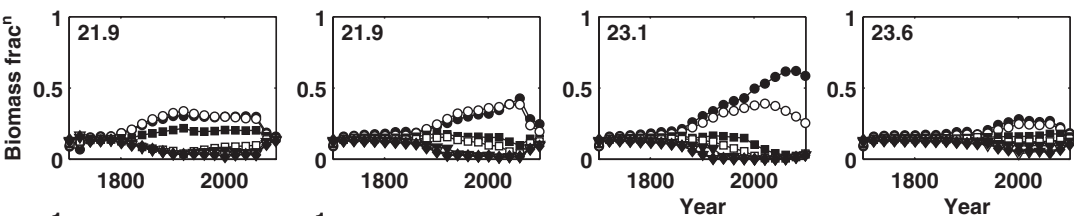
gross primary production (GPP), net primary productivity (NPP) and leaf area index (LAl). Panels are arranged according to the biomass predicted in 2050, to illustrate the impact of community composition on ecosystem prediction. Biomass in 2050 for each run is shown in text on each figure. Symbols refer to different PFTs: closed circles, PFT1; open circles, PFT2; closed squares, PFT3; open squares, PFT4; closed triangles, PFT5; open triangles, PFT6; closed diamonds, PFT7; open diamonds, PFT8.

community structure affects whole-ecosystem properties (GPP, NPP LAI and biomass) used in the filtering process. Typically, those ecosystems with a PFT range close to 1 had high values of GPP, NPP and LAI, which were often outside the observational range. Ecosystem biomass was greatest for mid-range community composition. Those ensemble members with highly equitable PFT distribution tended to have very low biomass, below the acceptable range.

Figs 5-7 illustrate how the five demographic parameters that we investigated were related to PFT range index (Eqn 10, Fig. 5), biomass predictions at 2050 (Fig. 6) and
LAI in 2005 (Fig. 7). The impact of the different parameters on NPP, GPP and biomass in 2005 and biomass in 2100 are illustrated in Figs S1-S4.

Of the five parameters varied, sapling mortality $\left(M_{s}\right)$ had the greatest impact on community structure and ecosystem properties. To illustrate the impact of varying this parameter on the model output, we shaded the points in Figs 4-7 according to their value of $M_{\mathrm{s}}$. $M_{\mathrm{s}}$ mediates the positive feedback between fast growth and sapling production. Those trees with fast growth rates produce large numbers of saplings that grow quickly during situations of (a)

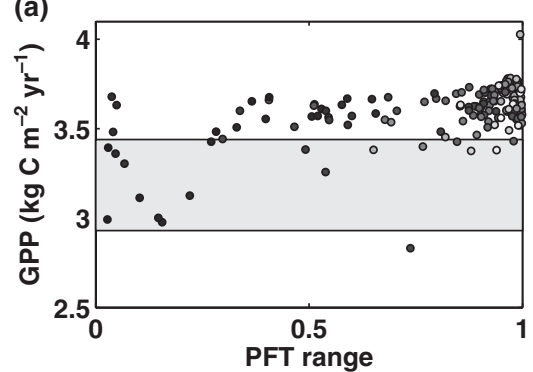

(c)

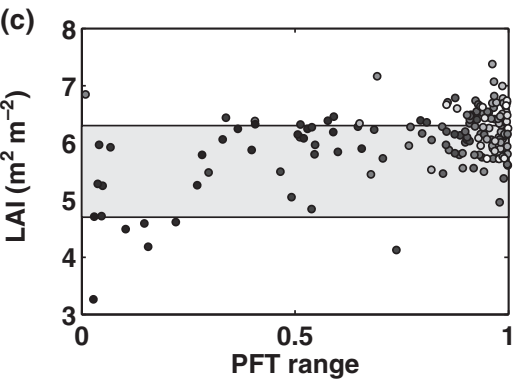

(b)

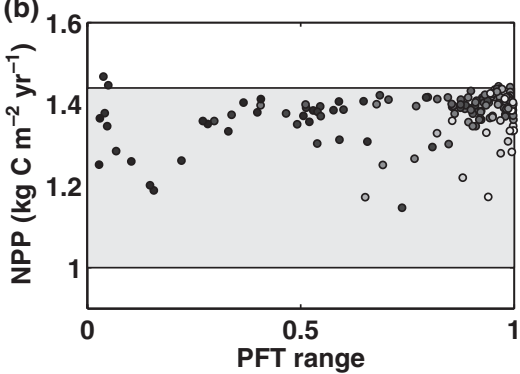

(d)

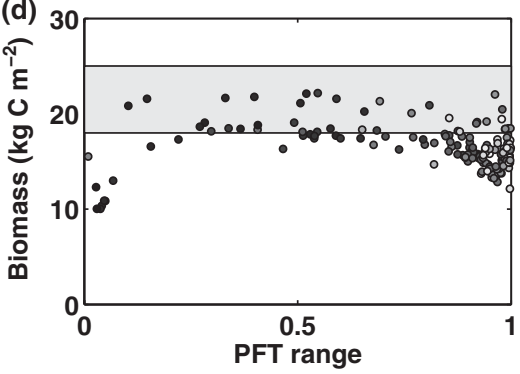

Fig. 4 Relationship between (a) gross primary production (GPP), (b) net primary productivity (NPP), (c) leaf area index (LAI) and (d) biomass in 2005, and ecosystem composition as expressed by the plant functional type (PFT) range metric (Eqn 10). The shaded area indicates the limits of observations. Shading on symbols indicates the sapling mortality $\left(M_{s}\right)$ parameter for each run, and can be read from Fig. 5(d). 
New
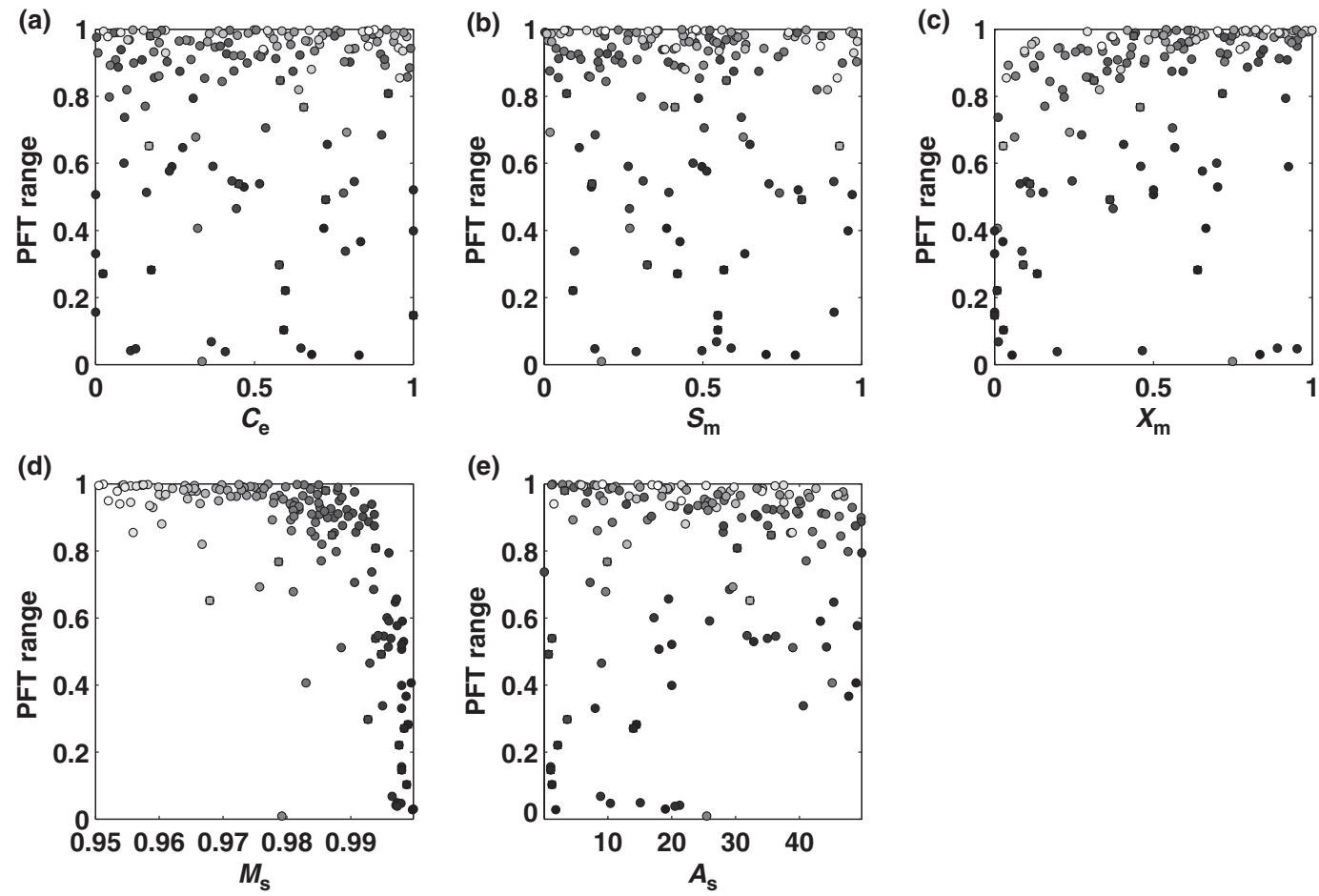

Fig. 5 Response of modelled plant functional type (PFT) range in 2005 to variation in (a) competitive exclusion, $C_{e}$, (b) stress-induced adult mortality, $S_{m}$, (c) seed mixing, $X_{m}$, (d) sapling mortality, $M_{s}$, and (e) seed advection, $A_{s}$. Shaded area denotes limits of observations from $M a l h i$ et al. (2009b). Square symbols denote members of the filtered ensemble with predictions of net primary productivity (NPP), gross primary production (GPP), leaf area index (LAI) and biomass within acceptable ranges. Shading on symbols indicates the sapling mortality parameter for each run, and can be read from panel (d).

low sapling mortality, increasing the tendency of fastgrowing PFTs to become dominant. Low values of $M_{\mathrm{s}}$ encourage this positive feedback, leading to monodominance and high PFT range. Simulations with high values of $M_{\mathrm{s}}$ suppress this feedback and tended to have a more equitable PFT distribution with more slow-growing PFTs (Fig. 5d). These PFTs are less susceptible to drought induced mortality (in the model), so the runs with high $M_{\mathrm{s}}$ have higher biomass in 2050 (Fig. 6d). In addition, a combination of higher allocation to storage, and less to leaves, as well as lower overall understorey recruitment rates, means that those communities with high values of $M_{\mathrm{s}}$ have lower estimates of LAI (Fig. 7d). The first order impact of lower sapling mortality on biomass (more seeds $=$ more biomass) was not present in 2005 (Fig. S3d).

The seed mixing parameter $\left(X_{\mathrm{m}}\right)$ had a large impact on community structure. Initial seeding conditions are an important control on community structure after canopy closure. When large numbers of seeds are distributed to other patches, and $X_{\mathrm{m}}$ is high, PFT1 dominance of one age class makes it a source of PFT1 seed for other age-classes, increasing its share of the seed bank and thus its increasing ability to dominate newly disturbed areas. Where most seeds land in their parent patch, and $X_{\mathrm{m}}$ is low, PFT1 wastes most of its seed increasing competition with itself. Therefore, high $X_{\mathrm{m}}$ promotes both dominance of PFT1 (Fig. 5c) and the development of communities with fastgrowing PFTs. These fast-growing PFTs are at greater risk of dying under future droughted conditions because of their lower carbon reserves, so forest biomass in 2050 is lower for high $X_{\mathrm{m}}$ simulations (Fig. 6c). However, higher $X_{\mathrm{m}}$ allows faster colonization of recently disturbed gaps, facilitating faster regeneration and higher spatially averaged LAI (Fig. 7c).

Seed advection $\left(A_{\mathrm{s}}\right)$ has a relatively minor impact on community structure and on biomass in 2050 (Fig 5e, 6 e). Increasing seed rain modulates the dominance of the fast-growing PFT for sapling recruitment, but also accelerates the rate of canopy closure, enhancing the dominance of the faster-growing plants (results not shown). The conflicting impact of these two mechanisms may well prevent any consistent response from emerging. $A_{\mathrm{s}}$ did have a notable impact on the biomass in 2100 (Fig. S2e), as higher seed rain presumably promotes a more rapid ecosystem recovery from mortality events (Fig. 7e). Higher seed advection also promotes higher LAI; the number of saplings present in the understorey increases on account of the shift in the equilibrium between recruitment and mortality. 

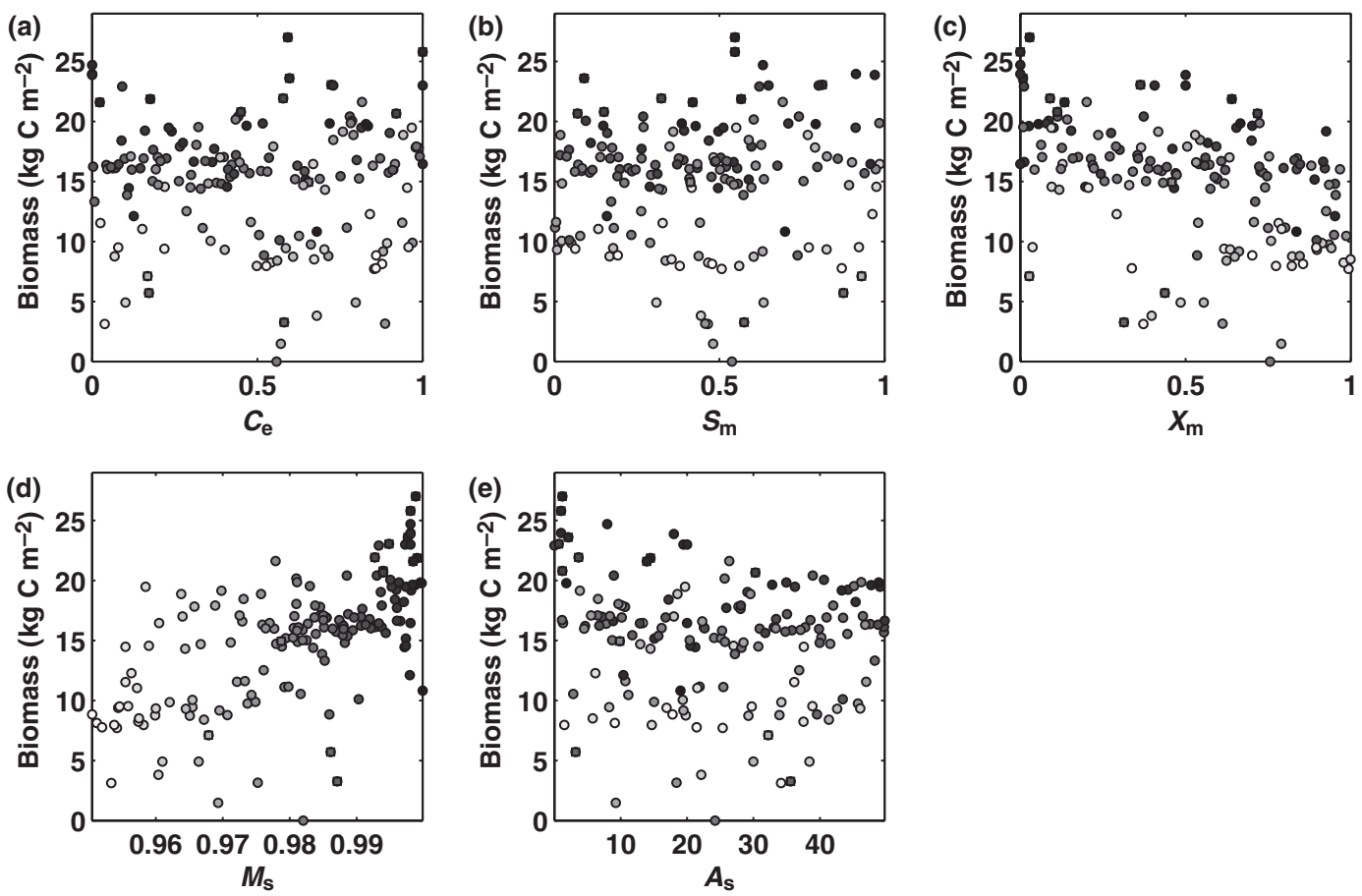

Fig. 6 Response of predicted biomass in 2050 to variation in (a) competitive exclusion, $C_{e_{r}}$ (b) stress-induced mortality, $S_{m}$, (c) seed mixing, $X_{m}$ (d) sapling mortality, $M_{s}$ and (e) seed advection, $A_{s}$. Square symbols denote members of the filtered ensemble with predictions of net primary productivity (NPP), gross primary production (GPP), leaf area index (LAI) and biomass within acceptable ranges. Shading on symbols indicates the sapling mortality parameter for each run, and can be read from panel (d).

There was little consistent effect of competitive exclusion $\left(C_{\mathrm{e}}\right.$, panel a, Figs 5 and 6$)$ or stress-induced mortality $\left(S_{\mathrm{m}}\right.$, panel b, Figs 5 and 6$)$ on either PFT composition (Fig 5) or biomass in 2050 (Fig 6) panel. In isolation, these parameters can exert substantial control over community structure (results not shown), but in the global sensitivity analysis (i.e. varying all parameters simultaneously) their impact may well have been overridden by large variations in the forcing caused by the other parameters. The LAI is highest for low values of $S_{\mathrm{m}}$, as greater mortality rates of carbon-starved plants in shade or drought results in a lower equilibrium LAI (Fig. 7b).

\section{Scale limitations and parameter constraints}

Typically, vegetation modellers attempt to constrain model parameter values via observations of the processes to which they apply. Unfortunately, the parameters we investigated here are not amenable to observation because the scales at which they operate are not represented in the spatially onedimensional model environment. For example, the rate of seed advection $A_{s}$ of a given PFT is likely a function of (at least) the mean distance in space to other areas of land containing that PFT. Landscape models that include a twodimensional spatial structure of interconnected patches, with a representation of both spatial arrangement and distance between patches, can simulate this property, but not one-dimensional DGVM models (Neilson et al., 2005; Lischke et al., 2006).

Similar issues apply to the other three parameters. Seed mixing, $X_{\mathrm{m}}$, most obviously, is the result of the unknown length scale of disturbance processes and patches of land that ED represents via statistical aggregation. The length scale of ecosystem patches in reality is controlled by the size of disturbance events. If most disturbance events result from the death of single trees, this generates a matrix with a small length scale and a consequentially high rate of inter-age class seed mixing. If mortality is spatially aggregated because of blow-down events, pathogen outbreaks or fires, then the length scale will be larger and mixing less likely. No DGVM at present tracks the two-dimensional sub-grid variation in disturbance history. Tracking disturbance history is only made computationally possible in the ED model by removing the spatial dimension and tracking all patches of a common disturbance history together. This property must therefore at present be parameterized. Here we illustrate, for the first time in the context of a DGVM modelling study, how the values of this property affect model outcome. Future studies must focus on resolving this issue either using top-down observational constraints, by leveraging output from spatially explicit studies into the one-dimensional model or by converting the model framework to a substantially more computationally intensive fine-mesh structure. 
New

Phytologist

(a)

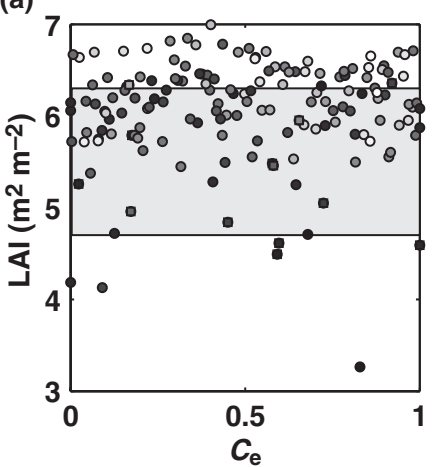

(d)

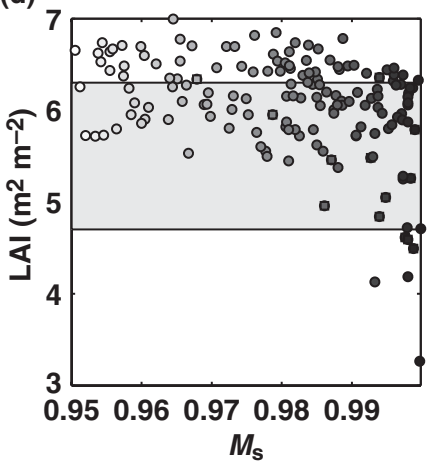

(b)

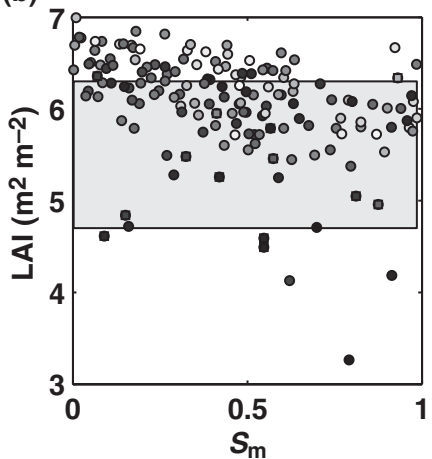

(e)

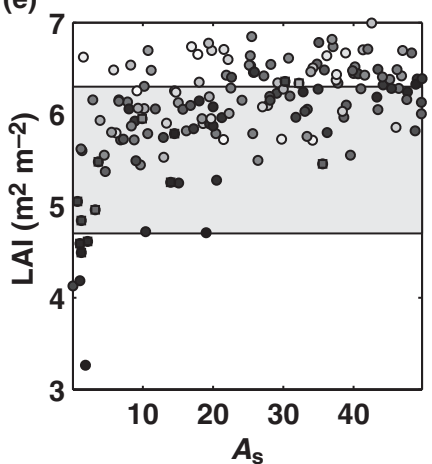

(c)

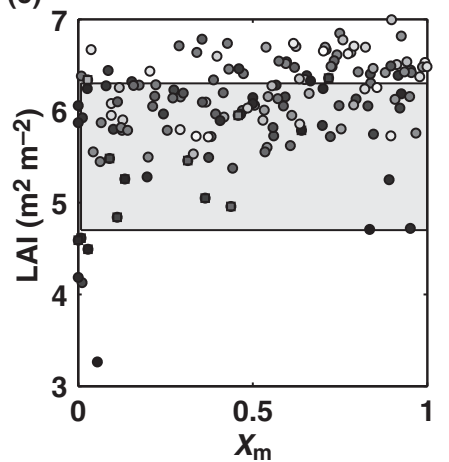

Fig. 7 Response of modelled leaf area index in 2005 to variation in (a) competitive exclusion, $C_{e}$, (b) stress-induced mortality, $S_{m}$ (c) seed mixing, $X_{m}$ (d) sapling mortality, $M_{s}$ and (e) seed advection, $A_{s}$. Shaded area denotes limits of observations from Brando et al. (2008) and Fisher et al. (2007). Square symbols denote members of the filtered ensemble with predictions of net primary productivity (NPP), gross primary production (GPP), leaf area index (LAI) and biomass within acceptable ranges. Shading on symbols indicates the sapling mortality parameter for each run, and can be read from panel (d).

The degree of determinism and stochasticity of competitive exclusion, $C_{\mathrm{e}}$, depends upon smaller-scale spatial interactions between the crowns of adjacent trees. Simulation of this process would require at least a branchscale canopy simulation model (Williams, 1996), in addition to improved understanding of the genetic heterogeneity between plants represented by a single PFT and the microvariation in abiotic conditions. It might be possible to estimate locally appropriate values of $C_{\mathrm{e}}$ from community composition data using inverse Bayesian methods (Clark et al., 2003; Etienne \& Olff, 2005).

Sapling mortality, $M_{\mathrm{s}}$, which is an aggregate of seed number, seed germination, and death of the germinated seedlings, is poorly understood and very complex to model mechanistically. Inverse estimates of seed mortality from forest inventories might be possible, but existing forest databases typically only measure trees $>10 \mathrm{~cm}$ diameter (Baker et al., 2004). Thus, estimates of $M_{s}$ are confounded with unobserved understorey growth and mortality processes. Also, sapling mortality is thought to be influenced by dispersal distance via the influence of species-specific herbivores or pathogens (Janzen, 1970; Connell, 1971) and by potential positive interactions between parent trees and saplings, the interactive consequences of which are explored by Murrell (2009).
Stress-induced mortality rates $\left(S_{\mathrm{m}}\right)$ appropriate for landscape-scale models or DGVMs are also difficult to parameterize. Allen et al. (2010) illustrate the difficulty of quantifying rates of vegetation mortality with observations made at multiple spatial scales. High rates of observed stand-level mortality typically translate into much lower landscape-level mortality rates, owing to spatial variation in landscape properties, biotic agents, species and weather (Allen et al., 2010). For a DGVM models, that scale linearly from plot-level simulations to landscape-level prediction, the appropriate scale of measurement of plant mortality rates is therefore contentious. Landscape-level estimates of tree mortality are very rare (Allen et al., 2010) but may be facilitated by vegetation monitoring networks (Phillips et al., 2009) in the future.

\section{Spatial interactions in existing studies}

The concept that spatial interactions are important for community structure is not novel (Silvertown \& Law, 1987) but is infrequently considered by the DGVM community (Neilson et al., 2005; Midgley et al., 2007). At present, no DGVMs represent the movement of propagules in two dimensions, and no first-generation DGVMs represent 
plant competition for light in a vertical profile (for a detailed review of first generation DGVM plant competition algorithms see Arora \& Boer, 2006). Literature from forest gap models discusses possible conditions necessary for simulating coexistence and the impact of competitive exclusion and spatial processes on community structure (Adams et al., 2007; Lischke \& Löffler, 2006; Kohyama \& Takada, 2009) but the emerging literature on second-generation DGVMs provides little discussion on how plant coexistence is generated along axes of variation other than early-to-late successional plant traits. A vast literature on the assemblage of communities, biodiversity and species coexistence can potentially inform us on how best to proceed from this point (McGill et al., 2006), and it seems likely that the possible limits on these parameters may potentially be informed by the outcomes of more spatially explicit models at various scales (Kneitel \& Chase, 2004).

\section{Conclusion}

In this paper we introduce a series of modifications to the ED model that more readily allow the coexistence of plant types with similar growth rates. We conclude that, despite major advances in dynamic global vegetation modelling, there exist a number of processes pertaining to spatial plant ecology that are currently beyond the capacity of even the most sophisticated DGVMs to capture. If we fail to appropriately represent or constrain the processes that control the emergence of plant community structure in the new generation of global vegetation models, we risk generating modelled communities of plants with erroneous responses to climatic and atmospheric changes.

While we have endeavoured to create simulations that closely reflect the behaviour of Amazonian rainforest ecosystems, we emphasize that our purpose was not to provide definitive predictions of the future of the Amazon, but instead to illustrate the potential importance of the representation of infrequently discussed plant demographic processes of reproduction, competition and mortality on the range of future predictions. We chose to focus on one location to allow a detailed illustration of this highdimension problem; however, it seems likely that the issues derived here may well be generically applicable, in different modelling frameworks, and across multiple combinations of climate and functional trade-off axes.

\section{Acknowledgements}

Funding was provided by the UK Natural Environment Research Council QUEST 'Quantifying Ecosystem's Role in the Carbon Cycle' project (QUERCC), the LANL/ LDRD program and DOE Office of Science (BER) Program for Ecosystem Research. R.F. thanks Craig Allen, Doug Clark, Micheal Dietze, Manuel Gloor, Heike
Lischke, Jon Lloyd, Mark Lomas, Oliver Philips, Colin Prentice, Todd Ringler, Allan Spessa, Ying-Ping Wang, Mark Westoby, Mat Williams and Ian Wright for interesting discussions that helped formulate the ideas in this manuscript.

\section{References}

Adams H, Guardiola-Claramonte M, Barron-Gafford GA, Camilo Villegas J, Breshears D, Zou CB, Troch PA, Huxman TE. 2009. Temperature sensitivity of drought-induced tree mortality portends increased regional die-off under global-change-type drought. Proceedings of the National Academy of Sciences, USA 106: 7063-7066.

Adams TP, Purves DW, Pacala SW. 2007. Understanding heightstructured competition in forests: is there an $R^{*}$ for light? Proceedings of the Royal Society B 274: 3039-3048.

Allen CD, Macalady A, Chenchouni H, Bachelet D, McDowell N, Vennetier M, Gonzales P, Hogg T, Rigling A, Breshears D et al. 2010. Climate-induced forest mortality: a global overview of emerging risks. Forest Ecology and Management. doi: 10.1016/j.foreco.2009.09.001.

Arora VK, Boer GJ. 2006. Simulating competition and coexistence between plant functional types in a dynamic vegetation model. Earth Interactions 10: 1-30.

Baker TR, Philips OL, Malhi Y, Almeida S, Arroyo L, di Fiore A, Erwin T, Killeen TJ, Laurance SG, Laurance WF. 2004. Variation in wood density determines spatial patterns in Amazonian forest biomass. Global Change Biology 10: 545-562.

Baraloto C, Goldberg DE, Bonal D. 2005. Performance trade-offs among tropical tree seedlings in contrasting microhabitats. Ecology 86: 24612472.

Bonan G, Levis S, Sitch S, Vertenstein M, Oleson K. 2003. A dynamic global vegetation model for use with climate models: concepts and description of simulated vegetation dynamics. Global Change Biology 9: $1543-1566$.

Bonan GB. 2008. Forests and climate change: forcings, feedbacks, and the climate benefits of forests. Science 320: 1444-1449.

Brando PM, Nepstad DC, Davidson EA, Trumbore SE, Ray D, Camargo P. 2008. Drought effects on litterfall, wood production and belowground carbon cycling in an Amazon forest: results of a throughfall reduction experiment. Philosophical Transactions of the Royal Society London, Series B 363: 1839-1848.

Carswell FE, Costa AL, Palheta M. 2002. Seasonality in $\mathrm{CO}_{2}$ and $\mathrm{H}_{2} \mathrm{O}$ flux at an eastern Amazonian rain forest. Journal of Geophysical Research 107: 8076.

Chao KJ, Philips OL, Gloor E, Montegud A, Torres-Lezama A, Vásquez Martínez R. 2008. Growth and wood density predict tree mortality in Amazon forests. Journal of Ecology 96: 281-292.

Clark JS, Dietze M, Chakrabotry S, Agarwai PK, Ibanez I, LaDeau S, Wolosin M. 2007. Resolving the biodiversity paradox. Ecology Letters 10: 647-662.

Clark JS, Mohan J, Dietze M, Ibanez I. 2003. Coexistence: how to identify trophic trade-offs. Ecology 84: 17-31.

Collatz GJ, Ball JT, Grivet C, Berry JA. 1991. Physiological and environmental regulation of stomatal conductance, photosynthesis and transpiration: a model that includes a laminar boundary layer. Agricultural and Forest Meteorology 54: 107-136.

Collatz GJ, Ribas-Carbo M, Berry JA. 1992. Coupled photo-synthesis stomatal conductance model for leaves of C4 plants. Australian Journal of Plant Physiology 19: 519-538.

Connell JH. 1971. On the role of natural enemies in preventing competitive exclusion in some marine animals and rainforests. In: den Boer PJ, Gradwell GR, eds. Dynamics of populations. Wageningen, the Netherlands: PUDOC, 298-312. 
Cox PM. 2001. Description of the 'TRIFFID' dynamic global vegetation model. Hadley Centre Technical Note no. 24, Met Office (available via http://www.metoffice.gov.uk/publications/HCTN/)

Cox PM, Betts RA, Bunton CB, Essery RLH, Rowntree PR, Smith J. 1999. The impact of new land surface physics on the GCM simulation of climate and climate sensitivity. Climate Dynamics 15: 183-203.

Cox PM, Betts RA, Collins M, Harris C, Huntingford C, Jones CD. 2004. Amazon dieback under climate-carbon cycle projections for the 21st century. Theoretical and Applied Climatology 78: 137-156.

Cox PM, Betts RA, Jones CD, Spall SA, Totterdell IJ. 2000. Acceleration of global warming due to carbon-cycle feedbacks in a coupled climate model. Nature 408: 184-187.

Cox PM, Harris PP, Huntingford C, Betts RA, Collins M, Jones CD, Jupp TE, Marengo JA, Nobre CA. 2008. Increasing risk of Amazonian drought due to decreasing aerosol pollution. Nature 453: 212-216.

Cox PM, Huntingford C, Harding RJ. 1998. A canopy conductance and photosynthesis model for use in a GCM land surface scheme. Journal of Hydrology 212-213: 79-94.

Essery RLH, Best MJ, Betts RA, Cox PM, Taylor CM. 2003. Explicit representation of sub-grid heterogeneity in a GCM land-surface scheme. Journal of Hydrometeorology 4: 530-543.

Etienne RS, Olff H. 2005. Confronting different models of community structure to species-abundance data: a Bayesian model comparison. Ecology Letters, 8: 493-504.

Falster DS. 2006. Sapling strength and safety: the importance of wood density in tropical forests. New Phytologist 171: 237-239.

Fisher RA, Williams M, Lobo do Vale R, Lola da Costa A, Meir P. 2006. Evidence from Amazonian forests is consistent with a model of isohydric control of leaf water potential. Plant, Cell \& Environment, 29: 151-165.

Fisher RA, Williams M, Lola da Costa A, Malhi Y, da Costa RF, Almeida S, Meir PW. 2007. The response of an Eastern Amazonian rain forest to drought stress: results and modelling analyses from a through-fall exclusion experiment. Global Change Biology 13: 1-18.

Friedlingstein P, Cox P, Betts R, Bopp L et al. 2006. Climate-carbon cycle feedback analysis. Results form the C4MIP model intercomparison. Journal of Climate 19: 3337-3353.

Friend AD, White A. 2000. Evaluation and analysis of a dynamic terrestrial ecosystem model under preindustrial conditions at the global scale. Global Biogeochemical Cycles 14: 1173-1190

Gibon Y, Pyl ET, Sulpice R, Lunnj E, Höhne M, Günther M, Stitt M. 2009. Adjustment of growth, starch turnover, protein content and central metabolism to a decrease of the carbon supply when Arabidopsis is grown in very short photoperiods. Plant, Cell \& Environment 32: 859-874.

Hacke UG, Sperry JS, Wheeler JK, Castro L. 2006. Scaling of angiosperm xylem structure with safety and efficiency. Tree Physiology 26: 689701.

Harris PP, Huntingford C, Gash JHC, Hodnett MG, Cox PM, Malhi Y, Araujo AC. 2004. Calibration of a land-surface model using data from primary forest sites in Amazonia. Theoretical and Applied Climatology 78 $27-45$.

Hickler T, Smith B, Prentice IC, Mjöfors K, Miller P, Arneth A, Sykes MT. 2008. $\mathrm{CO}_{2}$ fertilization in temperate forest FACE experiments not representative of boreal and tropical forests. Global Change Biology 14: $1-12$.

Hikosaka K. 2005. Leaf canopy as a dynamic system: ecophysiology and optimality in leaf turnover. Annals of Botany 95: 521-533.

Hodnett MG, Da Silva SP, Da Rocha HR et al. 1995. Seasonal soil water storage changes beneath central Amazonian rainforest and pasture. Journal of Hydrology 170: 233-254.
Huntingford C, Cox PM. 2000. An analogue model to derive additional climate change scenarios from existing GCM simulations. Climate Dynamics 16: 575-586.

Huntingford C, Fisher RA, Mercado L, Booth BBB, Sitch S, Harris PP, Cox PM, Jones CD, Betts RA, Malhi Y et al. 2008. Towards quantifying uncertainty in predictions of Amazon 'dieback'. Philosophical Transactions of the Royal Society B 363: 1857-1864.

Iman RL, Conover WJ. 1982. A distribution-free approach to inducing rank correlation among input variables. Communications in Statistics B11: 311-334.

Janzen DH. 1970. Herbivores and the number of tree species. American Naturalist 104: 501-528.

Jipp PH, Nepstad DC, Cassel DK, De Carvalho CR. 1998. Deep soil moisture storage and transpiration in forests and pastures of seasonallydry Amazonia. Climatic Change 39: 395-412.

Jupp TE, Cox PM, Rammig A, Thonicke K, Lucht W, Cramer W. 2010 Development of probability density functions for future South American rainfall. New Phytologist. doi: 10.1111/ j.1469-8137.2010.03368.x.

Kneitel JM, Chase JM. 2004. Trade-offs in community ecology: linking spatial scales and species coexistence. Ecological Letters 7: 69-80.

Kohyama T, Takada T. 2009. The stratification theory for plant coexistence promoted by one-sided competition. Journal of Ecology 97 : 463-471.

Körner C. 2003. Carbon limitation in trees. Journal of Ecology 91: 4-17.

Krinner G, Viovy N, de Noblet-Ducoudré N, Ogée J, Polcher J, Friedlingstein P, Ciais P, Sitch S, Prentice IC. 2005. A dynamic global vegetation model for studies of the coupled atmosphere-biosphere system. Global Biogeochemical Cycles 19: GB1015, doi: 10.1029/2003GB002199.

Leibold MA, Holyoak M, Mouquet N, Amarasekare P, Chase JM, Hoopes MF, Holt RD, Shurin JB, Law R, Tilman D et al. 2004. The metacommunity concept: a framework for multi-scale community ecology. Ecology Letters 7: 601-613.

Lischke H, Löffler TJ. 2006. Intra-specific density dependence is required to maintain species diversity in spatio-temporal forest simulations with reproduction. Ecological Modelling 198: 341-361.

Lischke H, Zimmermann NE, Bolliger J, Rickebusch S, Thomas JL. 2006. TreeMig: a forest-landscape model for simulating spatiotemporal patterns from stand to landscape scale. Ecological Modelling 199: 409-420.

Lloyd J, Patino S, Paiva RQ, Nardoto GB, Quesada CA, Santos AJB, Baker TR, Brand WA, Hilke I, Gielmann H et al. 2009. Variations in leaf physiological properties within Amazon forest canopies. Biogeosciences Discussions 6: 4639-4692.

Malhi Y, Aragao LEOC, Galbraith D, Huntingford C, Fisher RA, Zelazowski P, Sitch S, McSweeney C, Meir P. 2009a. Exploring the likelihood and mechanism of a climate-change-induced dieback of the Amazon rainforest. Proceedings of the National Academy of Sciences, USA. doi: 10.1073/pnas.0804619106

Malhi Y, Aragão LEOC, Metcalfe DB, Paiva R, Quesada CA, Almeida S, Anderson L, Brando P, Chambers JQ, da Costa ACL et al. 2009b. Comprehensive assessment of carbon productivity, allocation and storage in three Amazonia forests. Global Change Biology. doi: 10.1111/j.1365-2486.2008.01780.x.

Malhi Y, Timmons Roberts J, Betts RA, Killeen TJ, Li W, Nobre CA 2008. Climate change, deforestation and the fate of the Amazon. Science 319: 169-172.

McDowell NG, Pockman WT, Allen CG, Breshears DD, Cobb N, Kolb T, Plaut J, Sperry J, West A, Williams DG et al. 2008. Mechanisms of plant survival and mortality during drought: why do some plants survive while others succumb to drought? New Phytologist 178: 719-739. 
McDowell NG, Sevanto S. 2010. The mechanisms of carbon starvation: how, when or does it even occur at all? New Phytologist 186: 264 266.

McGill BJ, Enquist BJ, Weiher E, Westoby M. 2006. Rebuilding community ecology from functional traits. Trends in Ecology and Evolution 21: 178-184

Meir P, Cox PM, Grace J. 2006. The influence of terrestrial ecosystems on climate. Trends in Ecology and Evolution 21: 254-260.

Meir P, Metcalfe DB, Costa ACL. 2008. The fate of assimilated carbon during drought: impacts on respiration in Amazon rain forests. Philosophical Transactions of the Royal Society London, Series B 363 : 1849-1855.

Metcalfe DB, Meir P, Aragão LEOC, Lobo-do-Vale R, Galbraith D, Fisher RA, Chaves MM, Maroco JP, da Costa ACL, de Almeida SS et al. 2010. Shifts in plant respiration and carbon use efficiency at a large-scale drought experiment in the eastern Amazon. New Phytologist. doi: 10.1111/j.1469-8137.2010.03319.x

Mercado LM, Bellouin N, Sitch S, Boucher O, Huntingford C, Wild M, Cox PM. 2009. Impact of changes in diffuse radiation on the global land carbon sink. Nature 458: 1014-1018.

Mercado LM, Huntingford C, Gash JHC, Cox PM, Jogireddy V. 2007. Improving the representation of radiation interception and photosynthesis for climate model applications. Tellus B 59: 553-565.

Midgley GF, Thuiller W, Higgins SI. 2007. Plant species migration as a key uncertainty in predicting future impacts of climate change on ecosystems: progress and challenges in terrestrial ecosystems in a changing world, global change - The IGBP series. In: Canadell JG, Pataki DE, Pitelka LF, eds. Terrestrial Ecosystems in a Changing World. Berlin Heidelberg, Germany: Springer 128-137.

Moorcroft PR. 2006. How close are we to a predictive science of the biosphere? Trends in Ecology and Evolution 21: 400-407.

Moorcroft PR, Hurtt GC, Pacala SW. 2001. A method for scaling vegetation dynamics: the ecosystem demography model (ED). Ecological Monographs 71: 557-586.

Murrell DJ. 2009. On the emergent spatial structure of size-structured populations: when does self-thinning lead to a reduction in clustering? Journal of Ecology 97: 256-266.

Neilson RP, Pitelka LF, Solomon AM, Nathan R, Midgley GF, Fragoso JMV, Lischke H, Thompson K. 2005. Forecasting regional to global plant migration in response to climate change. Bioscience 55: 749-759.

Nepstad DC, Decarvalho CR, Davidson EA, Jipp PH, Lefebvre PA, Negreiros GH, Dasilva ED, Stone TA, Trumbore SE, Vieira S. 1994. The role of deep roots in the hydrological and carbon cycles of Amazonian forests and pastures. Nature 372: 666-669.

Nepstad DC, Sitckler CM, Soares-Filho B, Merry F. 2008. Interactions among Amazon land use, forests and climate: prospects for a near-term forest tipping point. Philosophical Transactions of the Royal Society. Series B 363: 1737-1746.

Osada N, Takeda H, Kitajima K, Pearcy R. 2003. Functional correlates of leaf demographic response to gap release in saplings of a shade-tolerant tree Elateriospermum tapos. Oecologia 137: 181-187.

Pacala SW, Canham CD, Saponara J, Silander JA Jr, Kobe RK, Ribbens E. 1996. Forest models defined by field measurements: estimation, error analysis, and dynamics. Ecological Monographs 66: 1-44.

Phillips OL, Aragão LEOC, Lewis SL, Fisher JB, Lloyd J, LópezGonzález G, Malhi Y, Monteagudo A, Peacock J, Quesada CA, et al. 2009. Drought sensitivity of the Amazon rainforest. Science 323: 13441347.

Poorter L, McDonald I, Alarcón A, Fichtler E, Licona JC, Peña-Claros M, Sterck F, Villegas Z, Sass-Klaassen U. 2010. The importance of wood traits and hydraulic conductance for the performance and life history strategies of 42 rainforest tree species. New Phytologist 185: 481492.
Prentice IC, Bondeau A, Cramer W, Harrison SP, Hickler T, Lucht W, Sitch S, Smith B, Sykes MT. 2007. Dynamic global vegetation modeling: quantifying terrestrial ecosystem responses to large-scale environmental change. In: Canadell JG, Pataki DE, Pitelka LF, eds. Terrestrial ecosystems in a changing world. Berlin Heidelberg, Germany: Springer, doi: 10.1007/978-3-540-32730-1_15

Purves DW, Lichstein JW, Pacala SW. 2008a. Crown plasticity and competition for canopy space: a new spatially implicit model parameterized for 250 North American tree species. PLoS-One 2: e870.

Purves DW, Lichstein JW, Strigul N, Pacala SW. 2008b. Predicting and understanding forest dynamics using a simple tractable model. Proceedings of the National Academy of Sciences, USA 105: 17018-17022.

Purves DW, Pacala S. 2008. Predictive models of forest dynamics. Science 320: $1452-1453$.

Randerson JT, Hoffman FM, Thornton PE, Mahowald NM, Lindsay K, Lee YH, Nevison CD, Doney SC, Bonan G, Stöckli R et al. 2009. Systematic assessment of terrestrial biogeochemistry in coupled climatecarbon models. Global Change Biology 15: 2462-2484.

Reich PB, Wright IJ, Lusk CH. 2007. Predicting leaf physiology from simple plant and climate attributes: a global GLOPNET analysis. Ecological Applications 17: 1982-1988.

da Rocha HR, Goulden ML, Miller SD, Menton MC, Pinto Ldvo, de Freitas HC, Figueira A. 2004. Seasonality of water and heat fluxes over a tropical forest in eastern Amazonia. Ecological Applications 14: S22S32.

Rodenbeck C, Houweling S, Gloor M, Heimann M. 2003. $\mathrm{CO}_{2}$ flux history 1982-2001 inferred from atmospheric data using a global inversion of atmospheric transport. Atmospheric Chemistry and Physics 3: 1919-1964.

Sala A, Piper F, Hoch G. 2010. Physiological mechanisms of droughtinduced tree mortality are far from being resolved. New Phytologist 186: 274-281.

Salazar LF, Nobre CA, Oyama MD. 2007. Climate change consequences on the biome distribution in tropical South America. Geophysical Research Letters 34. URL http://www.agu.org/pubs/crossref/2007.../ 2007GL029695.shtml [accessed on 23 June 2010].

Sato H, Itoh A, Kohyama T. 2007. SEIB-DGVM: a new dynamic global vegetation model using a spatially explicit individual-based approach. Ecological Modeling 200: 279-307.

Scheiter S, Higgins SI. 2008. Impacts of climate change on the vegetation of Africa: an adaptive dynamic vegetation modelling approach. Global Change Biology 15: 2224-2246.

Selaya NG, Oomen RJ, Netten JJC, Werger MJA, Anten NPR. 2008. Biomass allocation and leaf life span in relation to light interception by tropical forest plants during the first years of secondary succession. Journal of Ecology 96: 1211-1221.

Sellers PJ, Berry JA, Collatz GJ, Field CB, Hall FG. 1992. Canopy reflectance, photosynthesis and transpiration III: a reanalysis using improved leaf models and a new canopy integration scheme. Remote Sensing and Environment 42: 187-216.

Sellers PJ, Mintz Y, Sub YC, Dalcher A. 1986. A simple biosphere model (SiB) for use within general circulation models. Journal of Atmospheric Science 43: 505-531.

Silvertown J, Law R. 1987. Do plants need niches? Some recent developments in plant community ecology. Trends in Ecology and Evolution 2: 24-26.

Sitch S, Huntingford C, Gedney N, Levy PE, Lomas M, Piao SL, Betts R, Ciais P, Cox P, Friedlingstein P et al. 2008. Evaluation of the terrestrial carbon cycle, future plant geography and climate-carbon cycle feedbacks using five dynamic global vegetation models (DGVMs). Global Change Biology 14: 1-25.

Sitch S, Smith B, Prentice IC, Arneth A, Bondeau A, Cramer W, Kaplans JW, Levis S, Lucht W, Sykes MT, et al. 2003. Evaluation of ecosystem 
dynamics, plant geography and terrestrial carbon cycling in the LPJ dynamic vegetation model. Global Change Biology 9: 161-185.

Smith AM, Stitt M. 2007. Coordination of carbon supply and plant growth. Plant, Cell \& Environment 30: 1126-1149.

Smith B, Prentice IC, Sykes MT. 2001. Representation of vegetation dynamics in modelling of terrestrial ecosystems: comparing two contrasting approaches within European climate space. Global Ecology and Biogeography 10: 621-637.

Sperry JS, Adler FR, Campbell GS, Comstock JP. 1998. Limitation of plant water use by rhizosphere and xylem conductance: results from a model. Plant, Cell \& Environment 21: 47-359.

Thornton PE, Lamarque J-F, Rosenbloom NA, Mahowald NM. 2007. Influence of carbon-nitrogen cycle coupling on land model response to $\mathrm{CO}_{2}$ fertilization and climate variability. Global Biogeochemical Cycles, 21, GB4018, doi: 10.1029/2006GB002868

Williams M. 1996. A three-dimensional model of forest development and competition. Ecological Modelling 89: 73-98.

Woodward FI, Lomas MR. 2004. Vegetation-dynamics - simulating responses to climate change. Biological Reviews 79: 643-670.

Wright IJ, Reich PB, Westoby M, Ackerly DD, Baruch Z, Bongers F, Cavender-Bares J, Chapin T, Cornelissen JHC, Diemer $\mathrm{M}$ et al. 2004. The world-wide leaf economics spectrum. Nature 428: 821827.

Würth MKR, Pelaez-Riedl S, Wright SJ, Korner C. 2005. Non-structural carbohydrate pools in a tropical forest. Oecologia 143: 11-24.

Zeng N, Mariotti A, Wetzel P. 2005. Terrestrial mechanisms of interannual $\mathrm{CO}_{2}$ variability. Global Biogeochemical Cycles 19: GB1016. (doi: 101029/2004GB002273).

\section{Supporting Information}

Additional supporting information may be found in the online version of this article.
Fig. S1 Response of predicted biomass at year 2005 to variation in (a) competitive exclusion, $C_{\mathrm{e}}$, (b) stress-induced mortality, $S_{\mathrm{m}}$, (c) seed mixing, $X_{\mathrm{m}}$, (d) sapling mortality, $M_{\mathrm{s}}$, and (e) seed advection, $A_{\mathrm{s}}$.

Fig. S2 Response of predicted biomass at year 2100 to variation in (a) competitive exclusion, $C_{\mathrm{e}}$, (b) stress-induced mortality, $S_{\mathrm{m}}$, (c) seed mixing, $X_{\mathrm{m}}$, (d) sapling mortality, $M_{\mathrm{s}}$, and (e) seed advection, $A_{\mathrm{s}}$.

Fig. S3 Response of predicted gross primary production (GPP) at year 2100 to variation in (a) competitive exclusion $C_{\mathrm{e}}$, (b) stress-induced mortality, $S_{\mathrm{m}}$, (c) seed mixing, $X_{\mathrm{m}}$, (d) sapling mortality, $M_{\mathrm{s}}$, and (e) seed advection, $A_{\mathrm{s}}$.

Fig. S4 Response of predicted net primary productivity (NPP) at year 2100 to variation in (a) competitive exclusion, $C_{\mathrm{e}}$, (b) stress-induced mortality, $S_{\mathrm{m}}$, (c) seed mixing, $X_{\mathrm{m}}$, (d) sapling mortality, $M_{\mathrm{s}}$, and (e) seed advection, $A_{\mathrm{s}}$.

Notes S1 Detailed description of JULES gas exchange model and algorithms controlling tree leaf area, canopy spread and physiological gradients within the forest canopy.

Please note: Wiley-Blackwell are not responsible for the content or functionality of any supporting information supplied by the authors. Any queries (other than missing material) should be directed to the New Phytologist Central Office.

\section{About New Phytologist}

- New Phytologist is owned by a non-profit-making charitable trust dedicated to the promotion of plant science, facilitating projects from symposia to open access for our Tansley reviews. Complete information is available at www.newphytologist.org.

- Regular papers, Letters, Research reviews, Rapid reports and both Modelling/Theory and Methods papers are encouraged. We are committed to rapid processing, from online submission through to publication 'as-ready' via Early View - our average submission to decision time is just 29 days. Online-only colour is free, and essential print colour costs will be met if necessary. We also provide 25 offprints as well as a PDF for each article.

- For online summaries and ToC alerts, go to the website and click on 'Journal online'. You can take out a personal subscription to the journal for a fraction of the institutional price. Rates start at $£ 151$ in Europe/\$279 in the USA \& Canada for the online edition (click on 'Subscribe' at the website).

- If you have any questions, do get in touch with Central Office (newphytol@lancaster.ac.uk; tel +44 1524 594691) or, for a local contact in North America, the US Office (newphytol@ornl.gov; tel +1 865576 5261). 